\title{
A LITERATURA INFANTIL PARA SURDOS POR MEIO DA LIBRAS
}

\author{
Maria Aparecida da Silva Barbosa ${ }^{1}$ \\ Marília Costa Pessanha Lara ${ }^{2}$
}

\section{RESUMO}

O objetivo deste trabalho é investigar o papel da literatura para crianças surdas na Educação Infantil. A partir das reflexões realizadas no Trabalho de Conclusão de Curso (BARBOSA, 2020), questiona-se qual é o papel e os benefícios da literatura para um povo e, especificamente, para uma população linguisticamente minoritária (no caso, a comunidade surda usuária de Libras). A metodologia empregada foi a revisão de textos acadêmicos sobre as temáticas de literatura, literatura infantil e literatura surda. Entende-se a literatura não como um item acessório, superficial, mas como um direito cultural de uma população (CANDIDO, 2011) e das crianças (MACHADO, 2002; CADEMARTORI, 2010). Quanto a modelos educacionais, analisamos a problematização das abordagens ditas bilíngues apresentadas em Perlin e Strobel (2008). Essas autoras propõem uma educação surda que dê protagonismo à surdez como diferença cultural, opondo-se a práticas oralistas ou bilinguistas superficiais. A partir de uma pedagogia surda orientada culturalmente, a literatura surda para crianças (adaptada ou autoral) é vista como elemento essencial da educação bilíngue/bicultural (LADD, 2013; MACEDO, 2012; ROSA, 2011, entre outros). Conclui-se que a pedagogia surda é um modelo que valoriza a cultura surda, sem constranger o indivíduo surdo a uma adesão à cultura majoritária ouvinte, e que se deveria explorar a literatura surda como um recurso pedagógico para o potencial da criança. A literatura, como um direito cultural das crianças surdas, precisa estar disponível em todos os espaços, especialmente nas escolas.

Palavras-chave: Literatura infantil. Literatura Surda. Pedagogia Surda. Educação bilíngue para surdos.

${ }^{1}$ Faculdade UNINA - Licenciada em Letras Libras-Português. E-mail: marryctba51@gmail.com

2 Faculdade UNINA - Mestre em Letras (Linguística).E-mail: mariliacosta.mcp@gmail.com 


\section{ABSTRACT}

The aim of this work is to investigate the role of literature for deaf children in early childhood education. Based on the reflections made during the course conclusion work (BARBOSA, 2020), the role and benefits of literature are questioned for a people and, specifically, for a linguistically minority population (in this case, the deaf user community pounds). The methodology used was the review of academic texts on the themes of literature, children's literature and deaf literature. Literature is understood not as an accessory, superficial item, but as a cultural right of a population (CANDIDO, 2011) and children (MACHADO, 2002, CADEMARTORI, 2010). As for educational models, we analyze the problematization of the so-called bilingual approaches presented in Perlin and Strobel (2008). These authors propose a deaf education that gives protagonism to deafness as a cultural difference, opposing superficial oral or bilingual practices. Based on a culturally oriented deaf pedagogy, deaf literature for children (adapted or authorial) is seen as an essential element of bilingual / bicultural education (LADD, 2013, MACEDO, 2012, ROSA, 2011, among others). We conclude that deaf pedagogy is a model that values deaf culture, without constraining the deaf individual to adhere to the majority listening culture, and that should explore deaf literature as a pedagogical resource for the child's potential. Literature, as a cultural right for deaf children, needs to be available in all spaces, especially in schools.

Keywords: Children's Literature. Deaf literature. Deaf Pedagogy. Bilingual Education for the Deaf.

\section{INTRODUÇÃO}

A interação com a literatura, seja esta escrita ou oral, é algo que se observa em diferentes culturas e em diferentes grupos etários. Mesmo antes da sua alfabetização, as crianças experimentam a literatura através da mediação de um ledor, que pode ser um professor, um cuidador ou até mesmo outra criança já alfabetizada. Desde essas primeiras experiências mediadas até a consolidação da leitura autônoma, observa-se uma forte relação entre a escola e a literatura infantil, não somente por ser o ambiente onde se dá o processo de alfabetização, mas por proporcionar uma série de experiências de formação de leitores. É no espaço escolar, como primeiro espaço social além da família, que a criança tem a oportunidade de manusear livros, participar de sessões de contação de 
histórias, frequentar a biblioteca escolar, interpretar e construir suas leituras na interação com os colegas. Essas e outras formas de experimentação literária explicitam que a construção do letramento literário se inicia desde a infância, em um ambiente de interação entre pares e com a cultura em que as crianças estão inseridas.

Ao pensarmos nas crianças surdas, às quais se propõe a língua de sinais e a experiência visual como forma de identificação com a comunidade e cultura surdas, questionamos qual é o papel da literatura no seu processo educacional. Trata-se de uma problemática que parte do acesso do aprendiz surdo aos contos infantis em Libras, mas que contempla também a função da literatura numa cultura e a estruturação do trabalho educacional (em especial, a elaboração de currículos) a partir de uma perspectiva cultural.

\section{A LITERATURA COMO UM DIREITO DAS CRIANÇAS}

A Literatura é uma manifestação artística que emerge do ser humano, uma criação que pode ser considerada uma obra prima e que representa a comunicação, a linguagem, a inovação e a arte com as palavras. Revela-se por meio da produção escrita, poética, ficção, drama e por meio de diferentes culturas e manifestações do universo dos homens em diferentes tempos e lugares, acompanhando a vida dos seres humanos em todas as civilizações, desde as mais antigas até a contemporaneidade. Candido (2011, p. 176), ao referir-se à literatura de uma forma ampla, define-a como sendo:

(...) todas as criações de toque poético, ficcional ou dramático em todos os níveis de uma sociedade, em todos os tipos de cultura, desde o que chamamos folclore, lenda, chiste, até as formas mais complexas e difíceis da produção escrita das grandes civilizações (CANDIDO, 2011, p. 176).

Seu registro faz parte da construção de todas as sociedades e se faz presente nos livros, nos jornais, nos muros das cidades, nas cartas, nos poemas e em diversas manifestações verbais, representando diferentes formas de expressão literária. Portanto, a literatura, também pode registrar a história de um 
povo ao referir-se à literatura de uma forma ampla.

Nesse sentido, o autor apresenta a literatura como um direito, e não como uma experiência acessória ou mesmo supérflua. Compara-se o direito à literatura como os direitos humanos à moradia, à alimentação, ao vestuário, à instrução e à saúde. Enquanto direito à instrução, também é imprescindível o direito à aquisição de conhecimentos por parte da literatura, direito este que deve ser estendido a todos os cidadãos e não somente a alguns. Dessa forma, uma boa leitura, enquanto direito de todos, inclusive da comunidade surda, é indispensável desde a infância, enquanto direito de igualdade de tratamento, transformando a teoria em prática.

Conforme Candido (2011), pensar em direitos humanos (aí incluídos o direito à arte e à literatura) necessariamente envolve esse tratamento igualitário a todas as pessoas, porque exige "reconhecer que aquilo que consideramos indispensável para nós é também indispensável para o próximo" (CANDIDO, 2011, p. 174).

A leitura de clássicos da literatura infantil deve estar presente na vida de todas as crianças desde o início do seu desenvolvimento e aprendizado, período em que são maiores as possibilidades de memorização do que foi ouvido ou lido. As histórias que são contadas na infância ficam gravadas na memória e sempre farão parte de reflexões presentes e futuras. Machado (2002), em seus escritos, traz a seguinte referência:

Engraçado como todas essas lembranças infantis ficam tão nítidas e duráveis. Talvez porque nas crianças a memória ainda está tão virgem e disponível que as impressões deixadas nela ficam marcadas de forma muito funda. Talvez porque sejam muito carregadas de emoção (MACHADO, 2002, p. 10)

A autora dá destaque ao direito que qualquer criança tem de acessar as obras clássicas da cultura ocidental, trazendo desde referências gregas (como fábulas de Esopo) até obras ficcionais ou religiosas, como os contos de fadas ou até mesmo a Bíblia. Esses seriam textos fundamentais que pertencem também às crianças surdas. Porém, ao pensarmos na situação dos surdos ou de outras minorias linguísticas e culturais, não podemos deixar de afirmar a relevância de uma literatura local, específica daquela comunidade. Quando o 
grupo cultural é minoritário, existe o perigo do seu apagamento diante da influência da cultura majoritária, muitas vezes massificadora.

Portanto, é necessário que ocorram registros da literatura na língua da comunidade surda, representando diferentes tempos e espaços de circulação (escolas, encontros comunitários, associações e agremiações, entre outros). Em especial, destaca-se a importância de evidenciarem-se os causos e histórias que possuem um valor cultural e de resgate dos seus antepassados (não genéticos, mas culturais), contadores de histórias. Conforme Karnopp (2008),

Além da importância dos registros na Libras, encontramos uma vasta e diversificada literatura, presente em associações de surdos, em escolas, em pontos de encontro da comunidade surda. Algumas dessas histórias são contadas e resgatadas por surdos idosos e/ou por surdos contadores de histórias. Uma pequena parcela dessas produções culturais tem sido registrada em fitas de vídeo, na Libras ou, então, traduzidas para a língua portuguesa. As narrativas, os poemas, as piadas e os mitos que são produzidos servem como evidências da identidade e da cultura surda (KARNOPP, 2008, p. 5-6).

Assim sendo, identificamos o valor dessa literatura produzida por surdos, quer na forma de literatura sinalizada (equivalente à literatura oral) ou literatura registrada em vídeos ou em traduções. Esse contato com a literatura infantil escrita e contada por surdos, com a qual a criança surda se identifica, refletirá como um modelo na sua vida, proporcionando prazer e estímulo para que amplie seu imaginário e comece a criar suas próprias histórias.

As autoras Perlin e Strobel (2008) discorrem sobre a cultura surda, que figura como um dos pressupostos da educação de surdos. Esta cultura carrega elementos que constituem as identidades surdas, bem como a relação de poder com as pessoas ouvintes e a produção de significados a respeito do próprio grupo de surdos e de outros grupos culturais.

Cultura surda é o jeito de o sujeito surdo entender o mundo e de modificá-lo a fim de torná-lo acessível e habitável ajustando-os com as suas percepções visuais, que contribuem para a definição das identidades surdas e das "almas" das comunidades surdas (PERLIN; STROBEL, 2008, p. 30). 
Por exemplo, Ladd (2013) traz um desses aspectos da cultura surda que é usado pela comunidade como forma de existir no mundo. Trata-se da manifestação do humor enquanto um comportamento de sobrevivência nas diversas situações, seja nos momentos difíceis ou de alegria. O autor apresenta o seguinte relato:

Um rapaz, a sua habilidade era o humor. Uma pessoa olha para ele e fica rendida. Se aparecia alguma coisa, ele tinha sempre um comentário espirituoso sobre isso. Se as pessoas estavam tristes ou deprimidas, ou se alguma coisa tinha corrido mal na escola, ou se se tinha estragado, ou se éramos todos castigados por alguma coisa, ou se o líder tinha de ser chamado, ele dizia alguma coisa para nos animar (LADD, 2013, p. 1004).

Observamos nessa passagem justamente o fenômeno descrito por Candido (2011), em que um valor cultural (a resistência) se manifesta e fixa numa comunidade através de um texto literário (uma narrativa humorística com uma linguagem elaborada, que deixa as pessoas "rendidas").

Rosa (2011) também ressalta o quanto a literatura surda é fundamental na identidade e na cultura do surdo. Está presente nas narrativas e tem importante contribuição no desenvolvimento de muitos surdos que não conhecem a sua própria língua, ou seja, desconhecem a Libras e, quando entram em contato com ela, estranham a sua existência e a própria cultura surda. O autor coloca que a literatura surda

(...) consiste nas histórias que a Libras possui, a questão da identidade e da cultura surda presentes na narrativa. Mas por que precisamos de uma Literatura Surda? Frequentemente encontramos muitos surdos que não conhecem sua própria língua. Ao conhecer a Libras, estranham saber que existe uma cultura surda. Dessa forma, a literatura surda pode auxiliar no conhecimento desta língua e da cultura para os surdos que ainda não têm acesso a elas. Para as crianças surdas, a literatura surda é um meio de referência e uma forma para criar uma aproximação com a própria cultura e facilitar o aprendizado da sua língua natural, que auxiliará na construção de sua identidade (ROSA, 2011, p. 32).

A comunidade infantil surda tem direito à literatura, à imersão no mundo 
da fantasia, das fábulas, das histórias fantásticas, poemas e contos, bem como ao acesso a obras que remetem a uma multiplicidade de estilos, envolvendo os principais momentos históricos que dão sustentação à construção política, social e identitária de um país. A literatura infantil tem o poder de envolver as crianças em uma aventura, e é um período em que ela adquire conhecimento da cultura, de sociedade, de comportamentos, de atitudes, valores e de manifestação artísticas. Houve um interesse da escola pela literatura infantil, o qual se deu em função da possibilidade do seu uso como um instrumento a serviço do ensino da língua, para que os estudantes alcançassem um amplo domínio verbal. Cademartori (2010) coloca que:

(...) É como entretenimento, aventura estética e subjetiva, reordenação dos próprios conceitos e vivências, que a literatura oferece, aos pequenos, padrões de leitura do mundo. Mas não foi movida pelo reconhecimento desse potencial que a escola, inicialmente, voltou-se para a literatura infantil. A educação formal passou a valorizar essa produção com vistas a interesses mais imediatos. Viu nela um bom instrumento do ensino da língua, modo de ampliar o domínio verbal dos alunos. Acredita-se no slogan "quem lê, sabe escrever" (CADEMARTORI, 2010, p. 6).

Vale ressaltar que é fundamental entender como a criança surda que desenvolve o Ser Surdo consegue compartilhar com outros surdos os significados presentes na cultura surda, na construção da identidade surda, na Libras, na literatura, na pedagogia surda, na história cultural surda, na arte surda, sobre o intérprete de Libras, sobre o trabalho para surdos, bem como sobre a subjetividade do povo surdo e como interagirem em sua própria cultura.

\section{A LITERATURA NA ESCOLA DE SURDOS}

Considerando essa construção do sujeito enquanto surdo, desde sua infância e através da interação cultural, olhamos para a escola que é proposta a essa população. Um ambiente escolar que desenvolva o hábito pela leitura, com ações pedagógicas que intensifiquem esse hábito é indispensável. A obra 
literária infantil precisa ser compreendida e absorvida pela criança, o que não é diferente para a criança surda, que também precisa ter a realidade e a fantasia presentes em seu mundo. Assim, é importante verificar a existência de materiais didáticos a serviço da literatura e o uso adequado desses materiais com as crianças não ouvintes.

A questão que distingue a educação de surdos da educação geral passa pelos tópicos de comunicação e linguagem, o que requer modalidades educacionais específicas. Tradicionalmente, compreende-se que a educação de surdos, ao longo dos séculos XIX e XX, foi marcada por três modelos: o oralismo, a comunicação total e o bilinguismo. Esses diferem entre si não só metodologicamente, mas em seus fundamentos filosóficos estruturais, considerando o papel da escola, a elaboração de currículos e o papel da linguagem e comunicação para a pessoa surda. Perlin e Strobel (2008), assim como vários outros autores na área dos Estudos Surdos, consideram o oralismo e a comunicação total como modelos inadequados por não permitirem que a experiência visual e a língua de sinais floresçam plenamente. No oralismo, entende-se a surdez como uma deficiência a ser minimizada pela estimulação auditiva e treino da fala, visando à aprendizagem da Língua Portuguesa; tem como objetivo fazer a reabilitação dessa criança em direção à "normalidade", a não-surdez. A Comunicação Total, reconhecida como uma educação bimodal, usa diferentes metodologias para permitir que o surdo alcance uma comunicação mais efetiva no contato com a língua majoritária do ambiente em que está inserido. Os recursos utilizados são sinais gesto-visuais, leituras dos movimentos labiais e corporais, escrita, uso de aparelhos de amplificação sonora, pistas auditivas e componentes da língua de sinais.

O bilinguismo, enquanto proposta de ensino, efetiva-se por meio da apropriação de duas línguas. Na escola bilíngue, a metodologia prioriza ensinar a Libras como a primeira língua e o Português escrito como segunda língua. Portanto, no bilinguismo, a criança precisa estar em contato com as pessoas fluentes em língua de sinais, principalmente dentro do ambiente familiar e com os educadores e os demais com que tenha contato, para que possa estar desenvolvendo a habilidade dessa língua. Conforme Perlin e Strobel (2008), 
a modalidade Bilíngue é uma proposta de ensino usada por escolas que se sugerem acessar aos sujeitos surdos duas línguas no contexto escolar. As pesquisas têm mostrado que essa proposta é a mais adequada para o ensino de crianças surdas, tendo em vista que considera a língua de sinais como primeira língua e a partir daí se passam para o ensino da segunda língua que é o português que pode ser na modalidade escrita ou oral (PERLIN; STROBEL, 2008, p. 15).

Entretanto, considerando que o bilinguismo é um direito consolidado juridicamente no Brasil há praticamente duas décadas com a Lei de Libras (BRASIL, 2002), questionam-se quais seriam as formas como de fato este tem sido implantado nas escolas que atendem os surdos. Perlin e Strobel (2008) levantam indagações sobre as práticas chamadas bilíngues, observando uma grande variação. Por exemplo, as autoras identificam práticas bilíngues com aspecto tradicional, em que o aluno surdo, na sala de aula, é submetido a uma imposição da língua oral majoritária, como numa versão mais recente do oralismo. O professor trabalha com ouvinte e surdo da mesma forma, apenas inserindo os sinais, como numa tentativa de igualar os processos de aprendizagem.

Há práticas bilíngues mais humanistas e liberais, que contemplam alguns esforços no sentido de prover recursos mais adequados ao estudante surdo, mas que ainda mantêm o aluno surdo em limitação de oportunidades de aprendizagem se comparado ao ouvinte. Ainda se observou um bilinguismo progressista, que reconhece alguns aspectos da diferença cultural entre o aluno surdo e ouvinte, mas ignora a história e a cultura do surdo, ou a conhece apenas de forma superficial.

A crítica principal das autoras a todas essas "versões" do bilinguismo é que elas colocam, como condição suficiente, apenas a presença dos dois códigos linguísticos, Libras e Português. Mais do que isso, a língua de sinais aparece como um caminho para que o surdo acesse a comunidade ouvinte majoritária, sendo meramente um meio para que o surdo alcance uma cultura mais interessante ou elevada. Observamos que é nessa perspectiva que se propõe a educação inclusiva bilíngue para surdos, conforme proposta na Política Nacional de Educação Especial na Perspectiva da Educação Inclusiva (BRASIL, 2008), 
em que estudantes surdos seriam integrados em classes majoritariamente de estudantes ouvintes com a mediação de intérpretes de Libras.

As autoras expõem esse caráter colonialista do que se chama bilinguismo no Brasil, apontando para o fato de que, mesmo suas versões mais progressistas, não superam esse impasse. Propõem então uma Pedagogia Surda, em que a cultura e história dos surdos desempenham um papel central desde a elaboração do currículo até a metodologia. Não se pensa em adaptar a escola ouvinte inserindo a língua de sinais através de intérpretes ou mesmo de professores sinalizantes, mas em um novo eixo orientador da experiência escolar surda como um todo.

A pedagogia surda se contrapõe aos métodos tradicionais, respeitando as diferenças culturais e trabalhando com uma nova modalidade de ensino sobre a identidade e a cultura surda. Essa modalidade é a que vai proporcionar ao surdo, sentir-se inserido no processo educativo, não tendo a imposição do ouvintismo sobre a cultura surda. É uma realidade almejada, por colocar em evidência o ser surdo, sua forma de apreender, seu histórico cultural e sua identidade.

A proposta da educação bilíngue que apresenta a pedagogia surda se fundamenta na priorização da cultura surda, na subjetivação e nas trocas culturais, ou seja, no respeito à diferença e na importância da mediação intercultural.

\section{CONSIDERAÇÕES FINAIS}

O estudo teve como meta analisar a literatura infantil para a criança surda e a sua contribuição como meio para a formação educacional, cultural e social, como também enquanto direito respaldado em legislação específica. A presença da literatura na escola e o acesso às obras literárias, por todos os estudantes, justifica a relevância da literatura específica para o sujeito surdo.

Por um lado, vimos a necessidade da tradução dos clássicos da literatura infantil para a libras, como forma de possibilitar o acesso a essa literatura da comunidade majoritária onde a criança surda está inserida. Enquanto direito 
de participação cultural do surdo, o acesso à literatura geral e aos contos clássicos precisa estar disponível em todos os espaços, portanto, faz-se necessário que eles estejam presentes nas escolas. Ao mesmo tempo, é fundamental que a criança acesse a literatura de seu grupo específico, nativa da comunidade surda. Obras em vídeo ou em texto, mas que retratem a experiência surda, a língua de sinais, a história cultural dos surdos e outras manifestações do Ser Surdo devem compor também o acervo literário das bibliotecas e das aulas para surdos.

No sentido de que o surdo possa se apropriar de uma experiência bilíngue e bicultural, apresenta-se a pedagogia surda como um modelo que valoriza a cultura surda e a não obrigatoriedade de adesão à cultura ouvinte, priorizando a subjetivação e as trocas culturais, ou seja, o respeito à diferença e a importância da mediação intercultural, o que se confirma nas leituras de Perlin e Strobel (2008).

Por meio dessas reflexões preliminares e a partir da concepção de literatura como um direito central de qualquer grupo cultural, a literatura surda para crianças destaca-se como um dos elementos centrais na construção de uma escola de fato inclusiva, que insira, em seu currículo, a pedagogia surda como filosofia educacional.

\section{REFERÊNCIAS}

BRASIL. Presidência da República. Subchefia de Assuntos Jurídicos. Lei $\mathbf{n}^{\circ} \mathbf{1 0 . 4 3 6}$, de 24 de abril de 2002, que dispõe sobre a Língua Brasileira de Sinais - Libras e dá outras providências. Disponível em http://www. planalto.gov.br/ccivil. Acesso em 24/06/2020.

BRASIL. Ministério da Educação. Política Nacional de Educação Especial na Perspectiva da Educação Inclusiva. Brasília, 2008. Disponível em http://portal.mec.gov.br/arquivos/pdf/politicaeducespecial.pdf. Acesso em 22/05/2021.

CADEMARTORI, Ligia. O que é Literatura Infantil. Coleção Primeiros Passos. Editora Brasiliense. Tatuapé (SP), 2010.

CANDIDO, Antônio. Vários Escritos. 5. ed. Ouro Sobre Azul. Rio de Janei- 
ro, 2011.

KARNOPP, Lodenir Becker. Literatura Surda. Universidade Federal de Santa Catarina. Licenciatura em Letras-Libras na Modalidade a Distância. Florianópolis (SC), 2008. Disponível em file:///C:/Users/Acer/Downloads/ Literatura_Surda_Texto-Base.pdf. Acesso no dia 20/11/2020.

LADD, Paddy. Em Busca da Surdidade. Surd'Universo. Livraria Especializada Lda. info@surdunverso.pt, 2013. MACÊDO, Michelle Araújo. A Literatura Infantil para crianças surdas. Universidade Católica de Brasília. Brasília, DF, 2012. Disponível em https:// drive.google.com/file/d/OBWIIJRnCJiOhOVZsaWIrN3VoaFk/view. Acesso em 24/06/2020.

MACHADO,ANA MARIA. Como e por que ler os clássicos universais desde cedo. Rio de Janeiro: Objetiva, 2002.

PERLIN, Gladis; STROBEL, Karin. Fundamentos da educação de surdos. Florianópolis. Universidade Federal de Santa Catarina (UFSC). Florianópolis (SC), 2008. Disponível em http://www.libras.ufsc.br/colecaoLetrasLibras/eixoFormacaoEspecifica/fundamentosDaEducacaoDeSurdos/ assets/279/TEXTO_BASE- Fundamentos_Educ_Surdos.pdf. Acesso em $14 / 07 / 2020$

ROSA, Fabiano Souto. Literatura surda: o que sinalizam professores surdos sobre livros digitais em Língua Brasileira de Sinais - LIBRAS. Dissertação de Mestrado. Universidade Federal de Pelotas - Faculdade de Educação. Pelotas (RS), 2011. Disponível em http://guaiaca.ufpel.edu.br/ bitstream/123456789/1699/1/Fabiano_Souto_Rosa_Dissertacao.pdf. Acesso em 05/10/2020. 